\title{
Long-term monitoring for adders: an evolving methodology
}

\author{
R.J. Hodges \& C. Seabrook \\ Kent Reptile and Amphibian Group, c/o KMBRC, Brogdale Farm, Brogdale Road, Faversham, Kent ME13 8XZ \\ E-mail: RickHodges123@gmail.com
}

\begin{abstract}
Currently, there is no recommended methodology for long-term population monitoring of European adders (Vipera berus). To open a debate on a preferred methodology, we describe an approach based on 10-years' experience of monitoring in a chalk grassland reserve. The main elements are: 1) selection of a site with areas offering contrasting environmental conditions; 2) detection of adders along standard survey paths (transects) combined with paired artificial refuges of corrugated iron and roofing felt that are essential for detecting immature stages; 3) recognition of individual adders based on head-scale and neck patterns; 4) frequent site visits throughout the reptile active season; and 5) adoption of an Encounter Index (E.I.) that combines data from standard paths and refuges and normalises them for variations in survey effort and for shifts between years in the encounter rates along paths and at refuges. E.I. values correlate strongly with the numbers of known adders in the reserve but in some years E.I. values have been disproportionally high. Future objectives of the project are to explain variations in detectability and to estimate adder detectability associated with the current monitoring approach. Effective long-term monitoring is achievable by deploying "sufficient" refuges and, within practical limits, maximising path lengths and site visits. Future analysis of our own results will likely confirm our methodology as a "rule of thumb" for adder monitoring on, at least, chalk grassland.
\end{abstract}

\section{INTRODUCTION}

Significant contributions to the conservation of adders have come from long-term monitoring programmes ( $\geq 10$ years). In Great Britain, the negative impacts of forestry activities have been highlighted by reports from the Wyre forest between 1978 and 2016 (Sheldon \& Bradley, 2016). Details of reproductive biology, sub-populations and the longevity of adders have emerged from studies on the Dorset Heaths from 1986 to 2003 (Phelps, 2004a, 2004b), and in Somerset and Wales from 1989 to 2002 (Phelps, 2007). More recently, a programme in Belgium initiated in 2000 has provided an important understanding of the survival rate of the immature stages and the crucial influence of this on population growth in lowland wet heaths (Bauwens et al., 2016; Bauwens \& Claus, 2018), indicating that conservation efforts should address summer habitats where young adders reside and forage.

Long-term monitoring, together with adequate gathering of data on other relevant variables, offers considerable opportunities. It may demonstrate the impacts of land management and future climate change; assist with the interpretation of short-term survey data by clarifying the relationship between detection rates and climatic variables; and may provide information on how life histories may vary based on the records of individual adders from birth to relative old age.

At a national level, long-term monitoring is needed in diverse habitat types and contrasting latitudes. Previous long-term studies have been undertaken using various methodologies although all have relied on purely visual survey, i.e. did not employ artificial refuges. For the future in Britain, a more coordinated approach to long-term adder monitoring with broad agreement on methodology is likely to yield greater comparability between studies and a better national effort for adder conservation. As a basis for discussion on preferred methodology, we present the methods adopted by a monitoring programme on chalk grassland in Kent (England) that has now passed its tenth year and is planned to continue for many years to come. The programme detects adders using a combination of standardised survey paths (transects) and artificial refuges.

\section{METHODS \\ Important features of the monitoring site}

The site is a chalk grassland wildlife reserve on the North Downs in west Kent (England) managed by the Kent Wildlife Trust. The reserve is bordered by open farmland, housing, woodland and, for a short stretch, by a road so that it is relatively isolated with little prospect of exchange with other adder populations. The site is managed by extensive cattle grazing, usually from August to November, and scrub clearance by hand. This arrangement keeps survey paths and refuge positions open so that there is no need to change them between years. The location of the monitoring site is not disclosed in this paper to protect both the adders and their habitat. 
The site consists of three areas that slope differently and present contrasting environmental conditions. The sloping areas are separated from each other by tall scrub (Fig. 1), with about $5 \%$ to $10 \%$ of each area covered in low scrub. Each area has a different aspect (Table 1): Area 1 slopes west into the relatively narrow Darenth valley, Area 2 slopes predominantly to the south-west, and Area 3 slopes predominantly south; the last two areas face into a wide open vale. The differences in topography give potential differences in exposure to climatic variables. These include duration and strength of sunshine exposure and wind action which together may give different desiccation rates. Across years these differences may have varying impacts on the populations of adders and other reptiles. This arrangement gives advantages over a more uniform site since in time informative comparisons may be made between the three areas themselves, and in the future one of the areas could provide better comparisons with sites elsewhere.

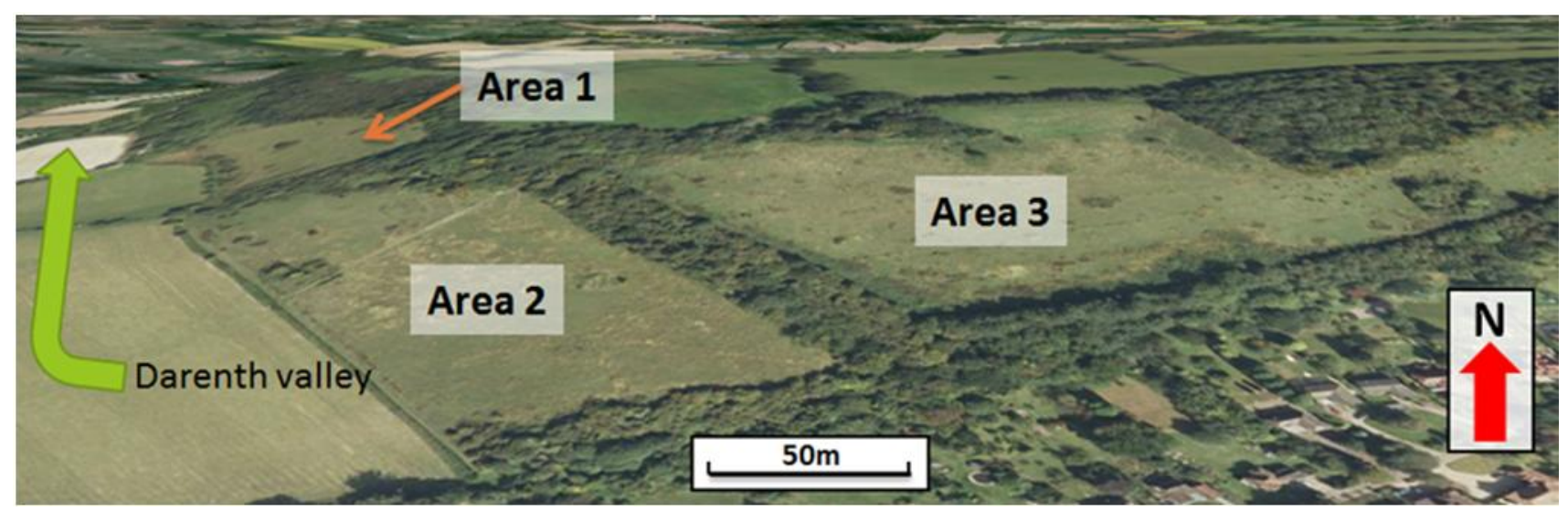

Fig. 1. Chalk grassland long-term monitoring site for adders (Vipera berus) on the North Downs in west Kent showing each of three contrasting areas (Areas 1, 2 and 3) separated by tall scrub. Details of each area are given in Table 1. (Photo: Google Earth)

\begin{tabular}{lccccccc}
\hline & $\begin{array}{c}\text { Main aspect } \\
\text { and slope }\end{array}$ & $\begin{array}{c}\text { No. refuge } \\
\text { positions }\end{array}$ & $\begin{array}{c}\text { Survey path } \\
\text { Length } \\
\text { (km) }\end{array}$ & $\begin{array}{c}\text { Path } \\
\text { length/refuge } \\
\text { pair (m) }\end{array}$ & $\begin{array}{c}\text { Area } \\
\text { (ha) }\end{array}$ & $\begin{array}{c}\text { Open area } \\
\text { Refuge } \\
\text { pairs /ha }\end{array}$ & $\begin{array}{c}\text { Survey path } \\
\text { (m)/ha }\end{array}$ \\
\hline Area 1 & $\begin{array}{c}\text { West, } \\
5-20^{\circ}\end{array}$ & 16 & 1.03 & 64 & 3.2 & 5.0 & 322 \\
Area 2 & $\begin{array}{c}\text { South-west } \\
5-20^{\circ}\end{array}$ & 14 & 0.89 & 64 & 2.7 & 5.2 & 330 \\
Area 3 & $\begin{array}{c}\text { South } \\
11-20^{\circ}\end{array}$ & 20 & 1.30 & 65 & 3.8 & 5.3 & 342 \\
\hline
\end{tabular}

Table 1. Details of three survey areas in a chalk grassland reserve on the North Downs in west Kent, managed by the Kent Wildlife Trust. Areas and path lengths measured on Google Earth. 


\section{Detecting adders}

Adders are observed along a standard survey path (transect) in each area. The paths run along the top, middle and bottom of each slope and vary in length more or less in proportion to the open space in each area at around $330 \mathrm{~m}$ path/ha (Table 1 ). In addition, there are pairs of felt and corrugated iron ("tin") artificial refuges, effectively fixed waypoints, along the survey paths. Refuge tins consist of galvanised corrugated-iron sheets $\left(0.5 \mathrm{~mm}\right.$ thick and $\left.0.5 \mathrm{~g} / \mathrm{cm}^{2}\right)$ and felts are prepared from domestic roofing felt (Garage felt, green slate finish, Homebase, \#242805, $2 \mathrm{~mm}$ thick and $0.3 \mathrm{~g} / \mathrm{cm}^{2}$ ). They are both cut to the same dimensions $(50 \mathrm{~cm}$ by $65 \mathrm{~cm}$ ) and pairs, comprising one of each type, are placed in sunny but inconspicuous locations backed by vegetation cover. To minimise disturbance by humans, tins are camouflaged by spraying their upper surface with brown paint (Espresso, satin finish, Rust-oleum). Refuges usually remain located in same position from year to year although are occasionally moved short distances away from ants nets or other problems. At the start of the study there were 31 refuge pairs but more were added so that at the time of writing there are 50 pairs. Consequently, from the start of monitoring to the time of writing the frequency of refuge positions along paths has risen from one every $104 \mathrm{~m}$ to one every $64 \mathrm{~m}$ (Table 1). The spacing of refuge positions is only roughly even along the paths, as priority is given to using less disturbed locations backed with good cover and the prospect of sunshine for at least some of the day. In relation to open space, the addition of refuge pairs over time resulted in an increase in density from 2.75.3 pairs/ha (Table 1). For general reptile monitoring the recommended density is $5-10$ refuges/ha (Froglife, 1999) but much higher densities are recommended for short-term, detailed assessments although in this case the critical factor is the distance of spacing between refuges (Reading, 1997; Schmidt et al., 2017).

Experiences with refuge use on the site in the period 2008 to 2015 have already been described in detail (Hodges \& Seabrook, 2016a). In summary, adult encounters along paths and at refuges both contribute significantly to records but immature stages were rarely encountered along paths so that records of them largely depend on the use of refuges. All life stages are encountered at tins more frequently than felts. Felts were included as although fewer adders were observed under them than tins, they are more effective for other species, especially slow worms (Anguis fragilis). In March and April, refuges are rarely used by adders and study of the thermal ecology of refuge use suggests that at this time of year it is usually more efficient for adders to be exposed to direct sunlight than to obtain warmth beneath a refuge (Hodges \& Seabrook, 2016b, 2016c). However, it should be noted that over the years there have been variations in the rates of observations along standard paths and at refuges, with a trend towards more observation along paths (Fig. 2). Consequently, the proportion of encounters at refuges has declined from $80 \%$ to $40 \%$. In due course this will need some explanation and may relate to changes in the prevalence of mature and immature adders, and influences of climate.

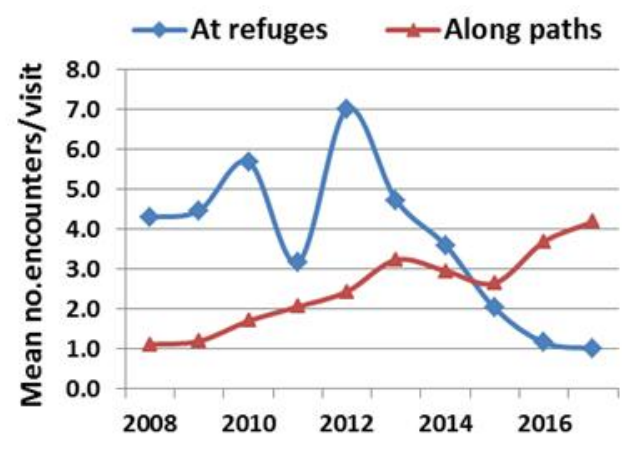

Fig. 2. Mean number of adder (Vipera berus) encounters/visit along paths and at refuges from 2008 to 2017 on the Kent long-term monitoring site. These data exclude neonates since these are observed only sporadically.

The survey team make 7 to 12 site visits per month from March through to the end of October, resulting in 56 to 78 annual visits for each of the last 10 years. A survey including all three areas can be completed in about 150 minutes and all areas are surveyed on each visit. Visits are only made on days when there is a reasonable prospect of encountering reptiles, i.e. not on heavily overcast days with dark cloud, significant rainfall, or temperatures below $8^{\circ} \mathrm{C}$. If weather allows, most site visits commence around $09.00 \mathrm{~h}$ and are initiated in Area 3 (Fig. 1) which receives any early sunshine. The rate of movement by surveyors around the site allows the sun to reach all three areas prior to survey and so optimises the chances of finding adders under refuges or basking in sunshine.

Life stages are defined as follows: neonates are in their year of birth before their first hibernation; juveniles have undergone a single hibernation; subadults that have undergone at least two hibernations. Males are adult when they have completed at least 4 hibernations and in the case of females they are adult after at least five hibernations. The life stages are known from a combination of their size, colour pattern and from individual records kept across years, but are likely subject to occasional inaccuracy. The gender of juveniles, sub-adults, and adults is determined by colouration and body proportions (Smith, 1951; Beebee \& Griffiths, 2000), although neonates and juveniles are likely more subject to errors.

\section{Individual recognition}

Recognition of individual adders is an important component of the study. Individuals are recognized by their head-scale and neck patterns (Benson, 
1999). Head-scale instability is thought to be rare; we have observed only a single case (Hodges \& Seabrook, 2014) and so this factor is unlikely to have any significant effect on our results. To minimise any disturbance, no adders are handled. Instead photographs are taken of adder heads either in the open at a distance of 2-4 m, using a long focal length lens, or much closer when individuals are under refuges. The scale patterns are coded and then entered into a database of our own design. To date there are records of 461 different individuals across all life stages. Of these adders, 45 (9.7\%) have been monitored successfully from their first year through to adulthood. Adders not seen for three years are assumed to be dead.

Individual recognition allows estimation of population size by the exclusion of repetitive counts of the same individual. It also allows the presence of individuals to be inferred when they are not recorded in every year. Furthermore, the individual count data can be used in the future for the analysis of detection rates and the impact on these of other variables, especially those relating to climate.

\section{Detection metrics}

Over time several components of the monitoring system have varied. In particular, there have been annual increases in the numbers of refuges deployed, variations in the numbers of site visits made, and as mentioned earlier, variation between the proportion of adders encountered at refuges and along paths (Fig. 2). In addition, the lengths of the survey paths differ between the three areas. These variations prevent simple comparisons in the encounter rate for adders, or other reptiles, between years and between areas. For this reason an Encounter Index (E.I.), a "normalising" metric, has been devised that gives equal weight to encounters at refuges and along paths and corrects for survey effort.

At the heart of the E.I. is the extent of monitoring infrastructure. This is defined for each area by reference to the length of the survey path along which records can be made and the number of refuge pairs along the path. As any changes in the number of refuge pairs or path length are on different scales, monitoring infrastructure is defined as the geometric mean of these two variables:

Monitoring infrastructure $=\sqrt{2}^{2}$ No. refuge pairs $\mathrm{x}$ path length)

Monitoring infrastructure has increased over the years and a measure of how thoroughly each area has been assessed can be obtained by considering monitoring infrastructure in relation to the number of hectares of open space present in each area (Fig. $3)$. In recent years (2016/2017), there has been strong convergence between areas in infrastructure per unit area making the three areas more readily comparable (Fig. 3).

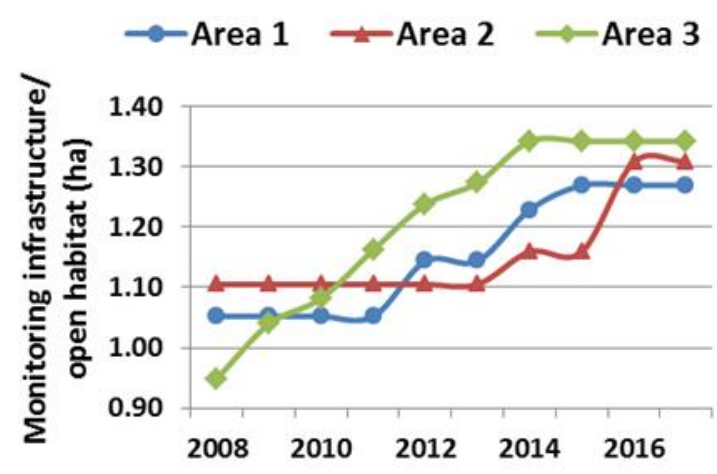

Fig. 3. Annual changes in monitoring infrastructure in Areas 1, 2 and 3 on the Kent long-term monitoring site relative to the amount of open space in each.

Monitoring effort for each year can be estimated by multiplying the monitoring infrastructure by the number of annual visits:

Monitoring effort $=$ monitoring infrastructure $\mathrm{x}$ no. annual visits

The E.I. for any particular year can then be estimated as the geometric mean of encounters at refuges (Encountersr) and those along the path (Encountersp), normalised by the annual monitoring effort as follows:

$$
\text { Encounter Index }=\frac{\sqrt{2}\left(\text { Encounters }_{\mathrm{r}} \times \text { Encounters }_{\mathrm{p}}\right)}{\text { Monitoring effort }}
$$

A plot of E.I. against the total un-normalised number of adder encounters shows the extent of correction made by adopting the E.I. (Fig. 4). As the variables were already kept within fairly close limits the corrections are relatively small.

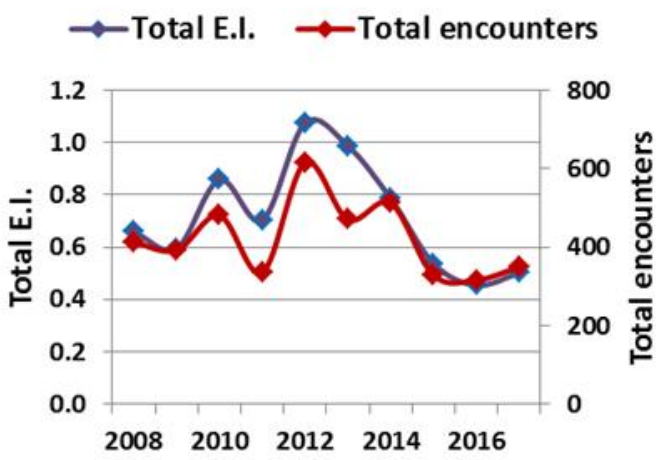

Fig. 4. Total Encounter Index (E.I) on the Kent long-term monitoring site (Areas 1, 2 and 3 combined) plotted with the un-normalised total number of adder (Vipera berus) encounters for 2008 to 2017 to show the extent of corrections made by the E.I.

It would be expected that the E.I. correlates strongly with the number of adders present on site, i.e. the more adders there are, the more will be encountered. When E.I. and the number of known adders on site (this excludes neonates as observations of these 
tends to be sporadic) are plotted together (Fig. 5), there is a strong positive correlation for the whole period of observation $(\mathrm{r}=0.73, \mathrm{df}=8, \mathrm{p}<0.02)$ and even stronger one for the period 2013 to 2017 (r = $0.92, \mathrm{df}=3, \mathrm{p}<0.05$ ). If, instead, the adder encounters from refuges and along the path (as shown in Fig. 2) had been simply summed, then the correlation with the number of known adders would have been weaker $(r=0.626, d f=8, p<0.1)$. It can be seen that adder encounters and the number of known adders have declined since 2012 (Fig. 5). Although this is generally the case, the three areas have behaved differently in this respect and by disaggregating the data by area a more informative picture will emerge during future, detailed analysis.

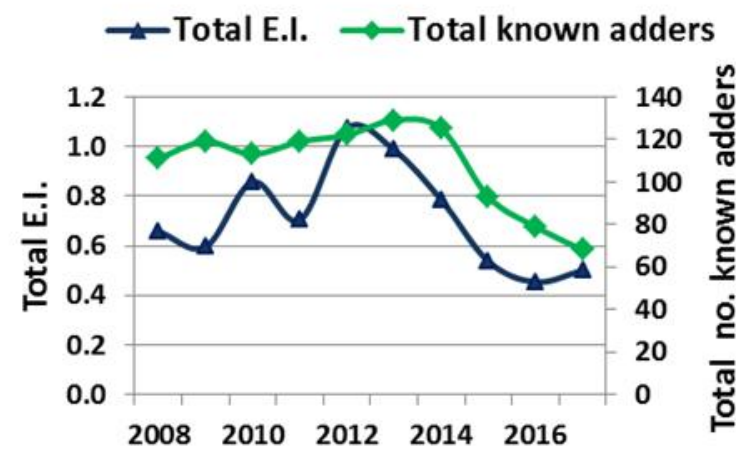

Fig. 5. Total Encounter Index (E.I) for the Kent long-term monitoring site (Areas 1, 2 and 3 combined) plotted with the number individual adders (Vipera berus) known to be on site 2008 to 2017, excluding neonates. NB: data for known adders in 2017 are still subject to increase by inference from 2018 and beyond.

An estimate of the extent to which the average adder is encountered each year can be made by dividing the E.I. by the number of known adders for that year. Such a plot (Fig. 6) demonstrates the especially high encounter rates in four out of ten years: 2010, 2012, 2013 and 2017. Preliminary analysis suggests that climatic factors may be responsible for this effect; it is a future task for the project to explain this in detail.

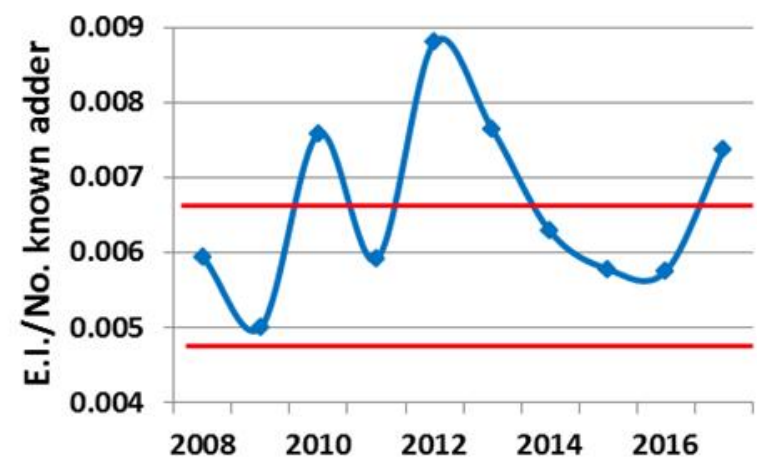

Fig. 6. Total Encounter Index (E.I) of Areas 1, 2 and 3 combined, on the Kent long-term monitoring site, corrected by the number of individual adders (Vipera berus) known to present on site each year 2008 to 2017, excluding neonates. Values falling outside red tram lines appear to represent exceptionally high encounter rates.

\section{Other variables being monitored}

Data are being gathered on other relevant variables. These include site management by grazing, presence of small mammals, and climatic factors. Live trapping of small mammals in September was undertaken from 2012 to 2015 to indicate food availability for adders at the end of the season. However, manpower constraints made this unsustainable. Climate data are collected both on site and from a private weather station at Tonbridge (Davis Vantage Pro2 Plus hardware, at N51 $11^{\prime} 2^{\prime \prime}, \mathrm{E} 0^{\circ} 15^{\prime} 34^{\prime \prime}$ and $148 \mathrm{~m}$ asl). The weather station is $16 \mathrm{~km}$ due south of the reserve. Daily data are provided free of charge and include temperature and humidity (mean, maximum and minimum for both), wind speed, and precipitation. Bright sunshine hours have been provided by a separate Tonbridge weather station but this ceased operation in October 2017 and, for the future, this variable will have to come from Heathrow, which is $48 \mathrm{~km}$ to the west. In addition, on site there are temperature loggers (Tinytag) placed in a shaded location. One logger is buried at $5 \mathrm{~cm}$ below the soil surface and the other is $30 \mathrm{~cm}$ above the soil surface. Since 2018, we have also been making records of soil moisture content to monitor desiccation.

\section{DISCUSSION}

For the long-term monitoring of adders on chalk grassland, a methodology employing both standard paths and artificial refuges has to date proved satisfactory, with refuge use essential for collecting data on immature stages. Likewise, a monitoring protocol using a standard path $(3 \mathrm{~km})$ along which corrugated iron refuges were placed (one per $136 \mathrm{~m}$ of path) was successfully adopted for grass snakes (Natrix helvetica) in Norfolk (Sewell et al., 2015), although there are several differences from the methodology describe here for adders. Previous advice on refuge deployment has typically expressed the number of refuges required as a proportion of the area of a site (Froglife, 1999). However, it is frequently unclear what sized area is actually being used by adders, i.e. it is unclear where the boundaries are to an adder population. Since the length of the survey path is known, this problem is avoided by expressing refuge deployment as the frequency of refuge positions along the length of the survey path, in this case one pair of felt/tin refuges for each $64 \mathrm{~m}$. This is equivalent to expressing refuge deployment in terms of the spacing in refuge arrays that are used in more intensive short-term monitoring of other reptiles (Reading, 1997; Schmidt et al., 2017).

The initial choice of a site with distinct areas of contrasting topography offers the prospect of useful comparisons based on differences in environmental conditions. However, care needs to be taken that lack of uniformity across a site does not accentuate any systematic biases in recording effort. In our case we ensured that the three different areas were given an 
equal chance of reptile observations by starting surveys at the area with the earliest sun and working round the site following the sun. Other precautions may be required at different sites.

When presenting monitoring results, these could be given as separate observations from the standard paths and from refuges. However, a metric, the E.I., is proposed that can be used to combine these two and normalise the data for varying effort between years and for shifts between years in the encounter rate along paths and at refuges. When plotted against an alternative (although not entirely independent) measure of adder abundance - the number of adders known to be present on site, there is a strong positive correlation with E.I. (Fig. 5). There are, however, deviations from this relationship (Fig. 6) where encounter rates appear exceptionally high. To date we have some evidence that these relate to responses to particular climatic conditions. This suggests that with more detailed analysis leading to correction of the E.I. for climatic variables, the revised E.I. might be taken as a proxy for the numbers of adders present on site.

An agreement on a preferred methodology for longterm adder monitoring would give useful future opportunities for comparability between studies. In the case of the methodology described here, estimation of the associated adder detection probabilities is still required to confirm its efficacy. There are also other some important considerations. In studies of other habitats (Griffiths et al., 2006; Walter \& Wolters, 1997; Reading, 1997) it appears that refuges have performed much less well than reported here on chalk grassland; it is not clear why this was the case. Also, undertaking long-term studies ( $>10$ years) is always a significant commitment and the number of annual site visits made in this study (59-78) requires a focused team effort, which is rarely available. It is possible that future analysis of our data may give some indication of the extent to which the visit rate could be lowered and still deliver equally useful results. Furthermore, if there are large numbers of individual adders that require recognition then using the freely downloadable Interactive Individual Identification System ( $\mathrm{I}^{3} \mathrm{~S}$, Version 4) software may make this element of the work quicker and easier. The E.I. needs to be explored further to confirm that it is robust for making comparisons between the results of different monitoring programmes especially in the absence of data on the numbers of known adders detected. At this stage it seems wise only to make comparisons where there monitoring infrastructure ratios are similar, i.e. in the range used in this study of one refuge pair per 64-104 m of path, which appears "sufficient". Less frequent refuge deployment is likely to provide poor data on the presence of immatures. For long-term monitoring, much increased refuge deployment is unlikely to be suitable for use in habitats where human visitors are frequent and aesthetic considerations important. In these situations effective monitoring is achievable by deploying at least "sufficient" refuges, while maximising path lengths and site visits within practical limits. Future analysis of our own results will likely confirm our methodology as a "rule of thumb" for adder monitoring on, at least, chalk grassland.

\section{ACKNOWLEDGEMENTS}

Our thanks to Richard Griffiths for very helpful comments on the manuscript, to Kent Wildlife Trust for permission to monitor on their reserve, and to their volunteers for the respect shown to our monitoring positions. This work was undertaken by volunteers of Kent Reptile and Amphibian Group in the context of the "Helping Adders Up Ladders" project.

\section{REFERENCES}

Bauwens, D. \& Claus, K. (2018). Do newborn adders suffer mass mortality or do they venture into a collective hide-and-seek game? Biological Journal of the Linnean Society 124, 99-112.

Bauwens, D., Claus, K., Hoeymans, B. \& Swert De, T. (2016). Populatiestudies en behoud van adders [Population studies and conservation of adders]. Natuur.focus 15(2), 59-66.

Beebee, T.J.C. \& Griffiths, R.A. (2000). Amphibians and Reptiles: a Natural History of the British Herpetofauna. The New Naturalist Series. HarperCollins, London.

Benson, P.A. (1999). Identifying individual adders, Vipera berus, within an isolated colony in East Yorkshire. The Herpetological Bulletin 67, 21-27.

Froglife (1999). Reptile survey. An Introduction to Planning, Conducting and Interpreting Surveys for Snake and Lizard Conservation. Froglife Advice Sheet $10 . \quad$ http://www.froglife.org/wpcontent/uploads/2014/01/FAS_10.pdf

(Accessed June 2018)

Griffiths, R.A., Sirsi, S. \& Webster, J.I. (2006). A comparison of tins and felts and their associated microclimates as artificial refugia for reptile. The Herpetological Conservation Trust and British Herpetological Society Joint Scientific Meeting: Amphibian and reptile biology, ecology and conservation. 16th December 2006, Bournemouth Natural Science Society.

Hodges, R.J. \& Seabrook, C. (2015). Head-scale instability and the apparent heritability of a head scale anomaly in the northern viper (Vipera berus). The Herpetological Bulletin 130, 16-17.

Hodges, R.J. \& Seabrook, C. (2016a). Use of artificial refuges by the northern viper Vipera berus - 1 . Seasonal and life stage variations on chalk downland. The Herpetological Bulletin 137, 6-12.

Hodges, R.J. \& Seabrook, C. (2016b). Use of artificial refuges by the northern viper Vipera berus - 2 . Thermal ecology. The Herpetological Bulletin 137, 13-18. 
Hodges, R.J. \& Seabrook, C. (2016c). Use of artificial refuges by the northern viper Vipera berus -3 . An experimental improvement in the thermal properties of refuges. The Herpetological Bulletin 137, 19-23.

${ }^{3} \mathrm{~S}$ (Version 4) Interactive Individual Identification System.

http://www.reijns.com/i3s/ (Accessed June 2018)

Phelps, T. (2004a). Population dynamics and spatial distribution of the adder Vipera berus in southern Dorset, England. Mertensiella 15, 241-258.

Phelps, T. (2004b). Beyond hypothesis - a long-term study of British snakes. British Wildlife 15, 319327.

Phelps, T. (2007). Reproductive strategies and life history traits of the Adder Vipera berus (Serpentes: Viperidae) in southern England and central Wales. The Herpetological Bulletin 102, 18-31.

Reading, C.J. (1997). A proposed standard method for surveying reptiles on dry lowland heath. Journal of Applied Ecology 34, 1057-1069.

Sewell, D., Baker, J.M.R. \& Griffiths, R.A. (2015). Population dynamics of grass snakes (Natrix natrix) at a site restored for amphibian reintroduction. Herpetological Journal 25, 155161.

Schmidt, B.R., Meier, A., Sutherland, C. \& Royle J.A. (2017). Spatial capture-recapture analysis of artificial cover board survey data reveals small scale spatial variation in slow-worm Anguis fragilis density. Royal Society Open Science 4, 1-8. http://dx.doi.org/10.1098/rsos.170374

Sheldon, S. \& Bradley, C. (2016). Wyre Forest Reptile Reports.

https://www.wyreforest.net/category/articles/ reptiles-and-amphibians-herpetofauna/ (Accessed May 2018)

Smith, M.A. (1951). The British Amphibians and Reptiles. The New Naturalist series. Collins, London.

Walter, G. \& Wolters, D. (1997). Die Effizienz der Reptilienaufnahme durch den Einsatz von Weißblech in Norddeutschland [The efficiency of reptile recording by the use of tin-plates in Northern Germany]. Zeitschrift für Feldherpetologie 4, 187-195. 